\title{
Da Escrita ao Registro da Cena na Dramaturgia do Espetáculo Quem Tem Boca, Vai a Roma, Quem Tem Sorte, ao Polo Norte
}

\author{
Fabiana Fontana \\ Universidade Federal de Santa Maria - UFSM, Santa Maria/RS, Brasil \\ E-mail: fontanafabiana@yahoo.com.br \\ Thayná Máximo de Almeida \\ Universidade Federal de Santa Maria - UFSM, Santa Maria/RS, Brasil \\ E-mail: thaynamaximo@hotmail.com.br
}

\begin{abstract}
O presente trabalho propõe analisar a dramaturgia do espetáculo de palhaço Quem tem boca, vai a Roma, quem tem sorte, ao Polo Norte como estratégia de discussão sobre a expansão do conceito dramaturgia no cenário cultural atual. Paralelamente, objetiva pensar o impacto desse fenômeno na investigação da dramaturgia como um dos vestígios do fazer artístico. Consequentemente, o trabaIho aborda alguns aspectos da problemática que abrange a documentação no teatro, mais especificamente, aquilo que se refere aos registros resultantes do processo de criação, os quais constituem, em parte, fontes de estudo da prática teatral.
\end{abstract}

\section{Palavras-chave}

Dramaturgia. Cena Contemporânea. Documento de Teatro. Palhaçaria. Processo Criativo.
The present work proposes to analyze the dramaturgy of the clown show Quem tem boca, vai a Roma, quem tem sorte, ao Polo Norte as a strategy to discuss the expansion of the dramaturgy concept in the current cultural scene. At the same time, it aims to think about the impact of this phenomenon on the investigation of dramaturgy as one of the traces of artistic making. Consequently, this work approaches some questions surrounding the documentation in the theater, more specifically, those that refers to the resulting records from the creative process, which are, in part, sources for the study of the theatrical practice.

Keywords

Dramaturgy. Contemporary Scene. Theater Archive. Clownery. Creative Process. 


\section{Dramaturgia: entre texto e cena}

Até as últimas décadas do século $X X, 0$ sentido de dramaturgia no teatro ocidental esteve vinculado estritamente ao texto teatral e ao drama. A partir de então, foram surgindo novos usos no emprego da palavra, sendo possível constatar que a abrangência, que hoje caracteriza o conceito, é recente. Segundo Walter Lima Torres Neto (2016), o fato pode ser notado pela crescente combinação do termo com outros elementos ou noções da cena no seio dos estudos teatrais: dramaturgia do corpo, dramaturgia do ator, dramaturgia do som etc.

A expansão do conceito deve, no entanto, ser percebida a partir da desestabilização dos elementos tradicionais do drama, fato que gerou a procura de novas formas de construir narrativas no teatro. Um dos fenômenos que abalaram a estrutura do drama, e colaboraram, assim, com a refração das noções dramáticas, é a aproximação do teatro com linguagens como a dança e a performance. (DANAN, 2010).

Consequentemente, com o tempo, foram surgindo poéticas que buscaram teatralizar o próprio teatro, ocasionando, muitas vezes, uma ruptura na distinção das duas etapas que antes caracterizavam a criação cênica: a análise do texto teatral e sua transposição para o palco. Se antes o foco era traduzir para o espaço aquilo que estava escrito, agora a atenção se torna a própria composição das ações que edificam a cena (NETO, 2016). O que se nota é uma transformação de orientação e concepção da gênese da ação no teatro, no âmbito do estudo da dramaturgia. Nesse sentido, a criação da ação não é, necessariamente, mais organizada pela fábula, noção fundamental no texto dramático, essencial para a construção de um outro lugar e um outro tempo para o qual o espectador era então levado (DANAN, 2019).

Bastante ilustrativa desse processo de transformação da dramaturgia enquanto conceito é a trajetória de Joël Pommerat, artista expoente da cena contemporânea francesa. Segundo ele, o desejo de se tornar autor o fez confrontar com "[...] a pesquisa sobre o espaço, o movimento, o som, a acústica, a luz, a iluminação, a interpretação, o figurino e mes- mo a produção" (POMMERAT, 2016, p. 21, tradução nossa). $\mathrm{O}$ artista esclarece ainda que esta mudança de paradigma, no que concerne à própria atividade de escrita na cena contemporânea, se relaciona com o fim da hierarquia entre os elementos cênicos, liderada então pela soberania do texto teatral no processo de criação. Sendo assim, se, para ele, no teatro, "há o silêncio, há o vazio e há os corpos", todos os elementos cênicos são, enfim, como "palavras do poema teatral” (POMMERAT, 2016, p. 22, tradução nossa).

O processo de expansão do conceito dramaturgia na cena contemporânea, representativo do aparecimento de poéticas outras que não fundamentadas na mimese, não deixou de impactar o debate sobre os documentos entendidos como registros do teatro. A desestabilização do logos, no interior do processo criativo, parece ter causado receios quando se trata dos vestígios que "sobram" da prática artística. Exemplo é a seguinte declaração sobre o assunto na perspectiva do pós-dramático:

Qual será a memória desse teatro na ausência de um texto que, até aqui, cumpria essa função? O vídeo? Uma partitura ainda por ser criada na qual estariam consignados dança, música, texto e os múltiplos elementos do espetáculo? Talvez o pós-dramático venha a ser um teatro sem memória ou cuja memória será necessariamente fragmentária. (BESSON, 2012, p. 147).

A desconfiança expressa nessa consideração se torna extremamente interessante, pois construída com base em juízos bastante discutíveis atualmente. Desde meados do século passado, a noção de registro do fazer artístico não se centra necessariamente no texto teatral, quando se atenta para a constituição do patrimônio documental do teatro (FONTANA, 2017). Além disso, mais recentemente, estudos dedicados ao processo criativo, como, por exemplo, os que se inserem no campo da genética teatral, eclipsam a possibilidade de um único vestígio servir como evidência de um fato nas artes cênicas. Isto porque o documento é considerado como traço de "um percurso artístico, destacando uma etapa da criação 
da obra" (FÉRAL, 2013, p. 570). Logo, fica explícita a condição de incompletude que cerca o vestígio da prática teatral, princípio que coaduna com a própria definição de documento de arquivo, em perspectiva mais geral; nessa, o registro é apenas a representação de uma ação ou atividade, e não o fato em si.

Para explorar a dramaturgia como escrita e um dos possíveis vestígios da cena, pretendemos analisar a dramaturgia do espetáculo Quem tem boca, vai a Roma, quem tem sorte, ao Polo Norte ${ }^{1}$. $O$ objeto de estudo se mostra bastante pertinente ao debate, dado que no universo onde a experiência se inscreve, a palhaçaria, as ações não se prestam necessariamente a "dar corpo" às palavras, pois sua criação está calcada na exploração do próprio modo de execução das ações em cena.

\section{A dramaturgia e a escrita da cena}

Quem tem boca, vai a Roma, quem tem sorte, ao Polo Norte é um espetáculo que se caracteriza pela ausência de diálogos ou falas e que não parte de nenhum material textual como base ou referência para a criação cênica. Seu processo criativo teve como inspiração inicial a palhaçaria russa, pouco investigada no contexto nacional; sendo assim, o vídeo do espetáculo SnowShow (2016), do palhaço russo Slava Polunin, foi adotado como a principal fonte para o estudo do tema.

O registro audiovisual de SnowShow acabou se configurando não só o documento que melhor serviu ao estudo do tema que constituiu o ponto de partida do espetáculo em questão, como determinou uma das etapas do seu processo criativo: os ensaios dedicados à análise de registros audiovisuais de espetáculos de palhaços russos, assim como de demais artistas inscritos no mundo da palhaçaria ou do circo. Este período de estudos era realizado essencialmente através da visualização de cenas, disponíveis na

1 O espetáculo, dirigido por Thayná Máximo e orientado pela Prof. ${ }^{a}$ Dr. ${ }^{a}$ Fabiana Fontana, tem origem nas disciplinas de Encenação IV e Metodologia do Processo Criativo, do Curso Artes Cênicas - Bacharelado, da Universidade Federal de Santa Maria (UFSM). internet, com o intuito de resgatar ideias ou mesmo gestos elaborados em outros contextos de criação.

Essas referências foram de extrema importância para a formação do repertório dos atores envolvidos na montagem, estando, inclusive, relacionadas diretamente com a forma mais tradicional de disseminação de saberes no mundo da palhaçaria, calcada majoritariamente na transmissão oral e visual.

Tal forma de difusão baseia-se na prática da cópia, tão presente na aprendizagem do palhaço. De acordo com Fernando Cavarozzi, o palhaço de rua Chacovachi (2016), a prática de pegar emprestado recursos de outros artistas é tão característica da palhaçaria que gera um acervo universal de números (ou rotinas). Encontrados em diferentes regiões do mundo, esses são então adaptados segundo as circunstâncias onde são realizados e as pessoas que os atualizam. As "rotinas podem ser as mesmas, mas a apresentação é sempre única e irrepetível, porque as pessoas com quem você se comunica são distintas e porquê você mesmo varia a maneira de fazer as coisas [...]" (CHACOVACHI, 2016, p. 52).

No caso do processo criativo do espetáculo Quem tem boca, vai a Roma, quem tem sorte, ao Polo Norte, o SnowShow inspirou a eleição da neve como principal elemento na constituição de um universo ficcional explorado, no entanto, apenas como ambiente para a improvisação dos atores - principal procedimento na criação das ações do espetáculo e, consequentemente, de sua dramaturgia. Já de La veillée des abysses (2016), de James Thiérrée, ator e diretor suíço reconhecido pelas suas performances no âmbito do circo contemporâneo, foi "emprestada" a ideia de sacudir um tecido branco para representar a tempestade de neve, originando, como resultado do exercício da cópia, uma situação particular a ser explorada pelos palhaços.

Posteriormente, os ensaios práticos, de um modo geral, seguiram uma estrutura previamente elaborada: um aquecimento seguido de exercícios de improvisação e, por fim, a realização de conversas para o compartilhamento de apontamentos e ideias referentes ao trabalho como um todo. Quanto 
às situações propostas para improviso, objeto que mais interessa na discussão da construção da dramaturgia do espetáculo, essas foram planejadas a partir de situações simples, estando de acordo com a relação da improvisação com a comicidade:

Ao saber que irá improvisar, o tipo cômico não pode esquecer que a comicidade necessita de referencial para viabilizar o processo intelectual da plateia e para que isso seja transformado em riso, até mesmo no que concerne ao estranhamento (absurdo). O público deve identificar a premissa da situação elaborada e esta deve ser simples. (OLIVEIRA, 2012, p. 52).

Alguns exemplos de situações criadas para a improvisação, extraídas do universo ficcional escolhido, são: congelar de frio, construir um abrigo e um palhaço se perder do outro. Todas as ações que constituem partes dessas situações foram criadas seguindo três importantes aspectos da palhaçaria: "O ridículo (que pode assumir uma proporção grotesca), o absurdo (que é visto como sinônimo de surreal e tudo que vemos na escala do estranho e esquisito) e o jogo (como estratégia de conexão com a plateia e improvisação)" (REIS, 2013, p. 362).

Das situações simples, então, originaram as cenas do espetáculo, a partir da criação das ações contextualizadas apenas nestes elementos que caracterizam a arte do palhaço. Ilustra o fato, a situação "caminhar seguindo o trajeto indicado no mapa". Um dos palhaços, personagem da peça, andou de forma saltitante, ao criar uma trajetória recheada de obstáculos imaginários em seu caminho. Sua companheira de cena, reagindo ao exagero do seu parceiro, andou sem demonstrar nenhuma empolgação, apenas seguindo os passos do primeiro. Dessa forma, nota-se que, quando se trata das situações simples, a criação da ação tem como foco a forma como a tarefa inicial é desempenhada. Por conseguinte, concomitante à criação da ação, se dá o próprio delineado das relações que os palhaços estabelecem entre eles e com o espaço, no aqui e agora da situação vivida.
No que compete à discussão da dramaturgia, fica nítido que as ações presentes no espetáculo em questão podem ser distinguidas como aquelas que Joseph Danan (2019, p. 21) identificou como "ações que são antes de tudo cênicas", ao tratar da cena pósdramática. Já que, por surgirem em contextos tão rudimentares no que concerne à constituição de um acontecimento dramático, não podem ser entendidas como parte de uma fábula que guie ou embase o seu aparecimento no palco. Sendo assim, são ações que exigem outros modos de dramaticidade, a qual, no caso específico do palhaço, está fundamentada no princípio da sua comicidade. Nesse sentido, a ação, no âmbito da palhaçaria, é essencialmente a expressão da lógica do palhaço em relação ao mundo:

Essa lógica geralmente se mostra visivelmente diferente, distante, contrastante e estranha aos modos e lógicas sociais e cotidianas do comportamento dos seus espectadores. Quando este contraste de lógicas é apresentado com clareza, ele evidencia estranheza, diferença, desproporção, distância e a arbitrariedade das lógicas atuais dos espectadores. Esta perturbação ou choque nos chega sem nos expor a perigos, sem nos ofender seriamente, na maioria das vezes, e rimos. Rimos porque este choque de lógicas chega ludicamente aos nossos olhos como ridículo, absurdo e grotesco. (REIS, 2013, p. 301).

Voltando ao âmbito da criação da dramaturgia aqui analisada, é possível perceber que é essa lógica individual que embala, por si, a criação da ação quando se atenta para outra situação simples. Tratase de "preparar-se para uma batalha". Nela, um dos palhaços ao reagir à ação do outro, deixou nítidas suas convicções e crenças. Pois, quando um deles começou a treinar para uma luta com movimentos de boxe e flexões de braço, o outro apenas se ajoelhou e começou a rezar, indicando que somente a proteção divina seria estratégia superior à força do outro.

Foi, então, de improvisação em improvisação, baseadas todas elas em situações simples, que se deu grande parte da criação dos acontecimentos do espetáculo Quem tem boca, vai a Roma, 
quem tem sorte, ao Polo Norte, deflagrando que a criação das ações consiste na dramaturgia do paIhaço (REIS, 2013). Apenas num outro momento, posterior à criação dessas ações essencialmente cênicas, houve uma preocupação em organizar as cenas levantadas durante um mês de investigação. Foi decorrente desse ensejo pela constituição de um arranjo que nasceu a dramaturgia do espetáculo, no sentido material do conceito.

Mas não só as cenas oriundas das situações simples serviram à composição desse material. Nesse trabalho de montagem, a importação de cenas provenientes de outros contextos de criação, já existentes, continuou. Mais números que não se originaram necessariamente no interior do processo criativo do espetáculo aqui analisado foram recuperados na criação de sua dramaturgia. Trata-se, primeiro, de um número que compõem o repertório pessoal de um dos palhaços da peça, sua própria adaptação da mágica "Neve Chinesa", retirada do livro Hocus Pocus: uma história de mágicos magníficos e suas incríveis façanhas (KIEVE, 2008). O número consiste em transformar um pedaço de papel em flocos de neve, espalhando-os pelo palco com o vento produzido por um leque. Sua escolha se deu tanto pelo efeito visual produzido quanto pelo fato de ser um número já dominado por um dos atores; além disso, a cena tinha ligação estreita com a temática do espetáculo que vinha sendo criado.

Depois, foi recuperado e adaptado um número clássico, inscrito na tradição da palhaçaria, chamado "Lavadeira". Tradicionalmente, o número se resume em dois palhaços travestidos de lavadeiras que, portando bacias cheias d'água, começam a brigar. O conflito termina com um deles jogando confetes no público, provenientes de uma das bacias, trocada sem a percepção da plateia. A eleição desse número se deve à necessidade de haver na construção da dramaturgia do palhaço, número(s) de interação direta entre os artistas e o público, tornando-se um dispositivo que oferece "[...] pontos de partida para o atuante desenvolver a sua palhaçaria." (REIS, 2013, p. 300). No contexto do espetáculo criado, o número foi adaptado para ser uma guerra de bolas de neve, fabricadas com papel amassado. Dependendo da reação do público, a cena pode virar um combate que coloca em foco a ação criada a partir, exclusivamente, da relação daqueles que estão fisicamente em lados opostos: os do palco $X$ os da plateia.

Diante desse conjunto de cenas, de origens diversas, se deu a construção do enredo da peça. Para isso, primeiramente, foi anotado em pequenos papéis o nome das cenas levantadas, e, junto com os atores, buscou-se ordená-las numa linha narrativa com começo, meio, clímax e fim. Entretanto, tais noções dramáticas foram sendo utilizadas na composição de uma fábula muito simples, pois elas serviam apenas para auxiliar o encaixe das ações cênicas na disposição de uma sequência. Tratava-se de arranjar as cenas no curso do tempo.

Aos poucos, a linha narrativa do espetáculo se formou, ela se concentra em torno de dois paIhaços obstinados na sua missão de entregar cartas ao Papai Noel. Quanto à ação dramática, essa pode ser assim descrita: dois palhaços carteiros que pegam um mapa, caminham para direção errada, voltam ao ponto de partida, se perdem um do outro, preparam um abrigo para passar a noite, comem, congelam de frio, brigam e fazem uma guerra de bolinhas de neve, enfrentam uma nevasca, pensam em desistir da missão, mas, enfim, encontram o destinatário da correspondência e concluem a sua entrega. Nota-se que o caráter rudimentar da ação dramática é condizente com a simplicidade da fábula, pois tal característica reflete o fato desta última não ocupar a centralidade da dramaturgia, de modo que a ação dramática se converte na própria exposição das ações físicas, ou cênicas, do palhaço.

O mesmo fato pode ser observado por outra perspectiva: mesmo organizada a ação dramática, seu status, no interior do processo de criação, nunca foi definitivo. Pois ao transcrever a história criada para o caderno, a diretora do espetáculo dispôs os acontecimentos em uma sequência de post-its coloridos, onde cada um deles recebia o nome de uma cena. Dessa forma, durante os 
ensaios subsequentes, se houvesse a necessidade de trocar a ordem dos fatos, acrescentar novos números, ou mesmo remover qualquer material, a diretora poderia facilmente reordenar a posição de cada peça na composição da dramaturgia final, de modo a continuar a organizar um arranjo aberto às suas inúmeras possibilidades de definição.

A imagem (Fig. 1) a seguir é uma foto do caderno de encenação da diretora Thayná Máximo, apresentando a primeira versão da dramaturgia analisada.

Figura 1 - Dramaturgia preliminar do espetáculo Quem tem boca, vai a Roma, quem tem sorte, ao Polo Norte.

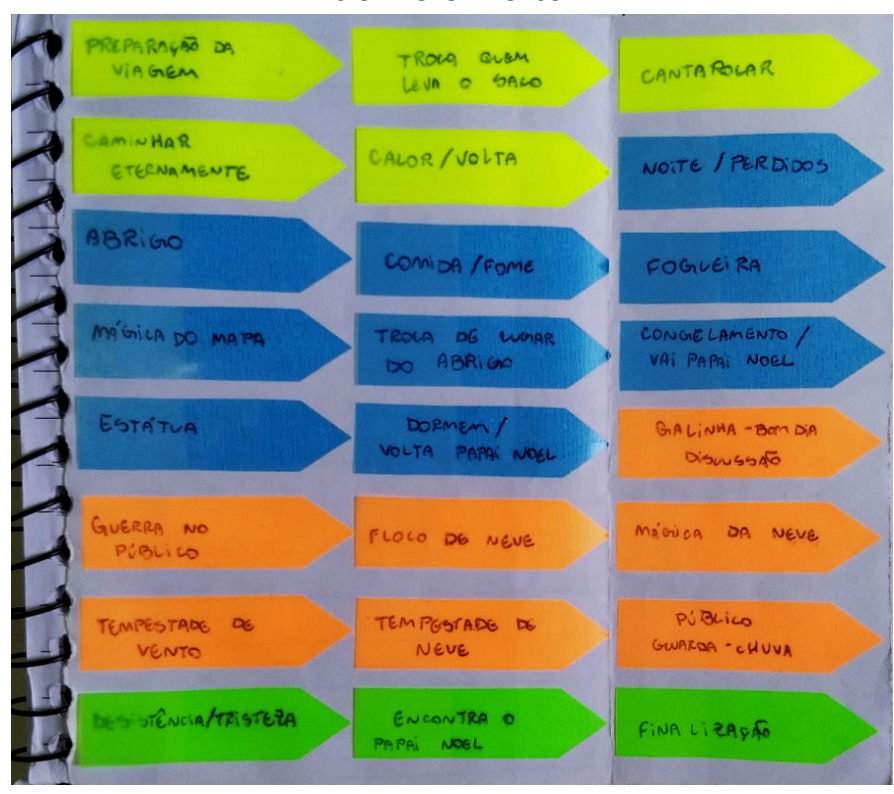

Fonte: Arquivo pessoal de Thayná Máximo.

Neste primeiro momento, as cores dos post-its se relacionavam à composição da estrutura da ação dramática do espetáculo, indicando a distribuição de suas partes em vista da manipulação do tempo na construção do ritmo do espetáculo. Amarela sinalizava o que era considerado início, azul para o meio, laranja indicava o clímax e verde o fim da peça. Posteriormente, na fase de composição da sua dramaturgia final, as cores dos post-its adquiriram um novo significado: a iluminação geral da cena. Vale ressaltar que esse elemento por si só já estava presente como base de algumas situações simples, os procedimentos-chave para a criação das ações do espetáculo. Em determinada cena, por exemplo, as luzes são apagadas e um dos palhaços usa um lampião para iluminar seu caminho, se assustando constantemente com o que encontra diante de si. A próxima imagem (Fig. 2) é uma foto de um trecho da dramaturgia final, onde é possível visualizar as mudanças de luz do espetáculo. Ao final de todo o documento, há uma legenda que explica a utilização das cores que em parte aparecem no fragmento aqui exposto, sendo: azul claro para luz branca; amarelo para luz amarela; azul escuro para luz azul escura e preto para luz apagada.

\section{Figura 2 - Dramaturgia final do espetáculo Quem} tem boca, vai a Roma, quem tem sorte, ao Polo Norte

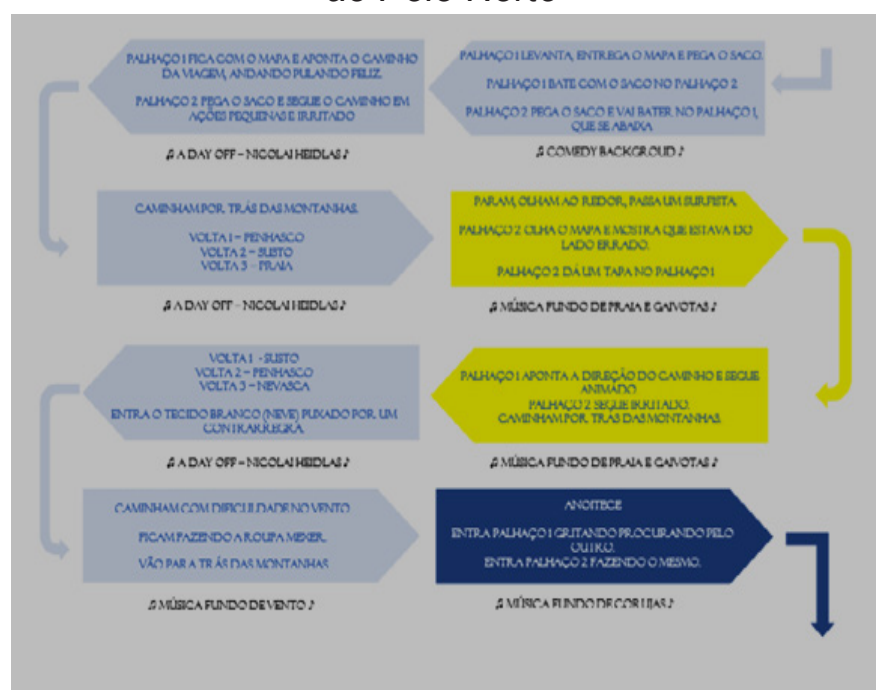

Fonte: Arquivo pessoal de Thayná Máximo

Com base na foto da dramaturgia final, é possível perceber que o posicionamento das palavras na construção do espaço gráfico da folha remete aos post-its usados no primeiro registro que serviu à sistematização das cenas, atividade compreendida no processo de fixação da dramaturgia da peça. Nessa última versão, as cenas já aparecem indicadas de forma mais detalhada nas setas onde estão escritas, indicando ora ações físicas, ora partituras, junto a elementos que constituem a atmosfera das cenas: ambientes, sons, adereços etc. O formato do documento tem como cerne para a sua configuração 
a indicação da sequência das cenas. Essa, não estando assegurada no desenrolar de um diálogo, necessitou ser expressa de outra maneira. Percebese, então, que esse documento final é resultado não só da ordenação dos acontecimentos, mas também é expressão do próprio processo criativo do espetáculo, pois nele estão revelados os elementos principais da sua escrita enquanto discurso cênico.

Dessa forma, a observação desse registro do fazer artístico esclarece o sentido que o termo dramaturgia ganhou como conceito, no fenômeno anteriormente mencionado como sendo a expansão do seu significado, no interior da cena contemporânea. Expressando a organização de criações, os artistas, agora, "[...] buscam no termo dramaturgia uma espécie de orientação para concatenar a obra cênica e sistematizar seu processo criativo." (NETO, 2016, p. 150).

Vale lembrar que, mesmo a dramaturgia descrevendo as principais ações e/ou partituras que os paIhaços devam realizar, esse documento não visa, ou mesmo possibilita, em todo, a fixação da ação. Dado que, no âmbito da palhaçaria, "[...] todo material levantado, consolidado no formato de estética de espetáculo, fica sujeito ao improviso, à adequação espacial e ao público." (OLIVEIRA, 2012, p. 55). Tal variação se estende ainda mais em amplitude quando se admite que o texto espetacular de Quem tem boca, vai a Roma, quem tem sorte, ao Polo Norte possa ser visitado por outros artistas que não aqueles que os criaram.

Tomando, então, a dramaturgia como um registro que objetiva contribuir para possíveis remontagens do espetáculo, ela só pode ser adotada como um documento pleno de inúmeros discursos corporais reciclados a partir do artista que (re)cria as ações nela sugeridas. Dessa forma, percebe-se que a dramaturgia deste espetáculo, mesmo servindo como retrato de um dos momentos conclusivos do processo de criação no qual tem origem, não deve ser entendida como uma obra acabada. Seu caráter instrumental the impõe uma condição de incompletude a ser atualizada constantemente por quem a toma como ferramenta para a criação cênica.
Logo, sua configuração, proveniente não só de sua origem como também da prospecção do seu uso, se mostra indissociável da função pragmática que a dramaturgia assume na criação de um acontecimento cênico.

\section{- A dramaturgia como um vestígio do teatro}

Danan (2017) alerta sobre a impossibilidade de definir a dramaturgia como decorrência do estado do teatro no tempo presente, justamente por sua configuração e significado serem recriados a cada espetáculo. Essa instabilidade, entretanto, não impede que a dramaturgia venha a ser discutida também em função de sua materialidade, como um dos tipos de documento oriundos da prática teatral, e, consequentemente, como um dos possíveis vestígios desse fazer. Nessa perspectiva, o termo pode, no seu alcance mais plural, sinalizar "que há uma nova forma de anotação (ou seria uma partitura?), minimamente sistematizada, cujo conteúdo é veiculado por meio da expressão dos signos, substantivos da cena." (NETO, 2016, p. 163).

Para análise deste documento, que consiste na estabilização de um discurso que usa a palavra para a ordenação do espaço-tempo do acontecimento cênico, parece ser fundamental uma observação acurada da prática artística que se configura como a conjuntura de sua produção. Pois é no interior do processo criativo que se encontram as razões de ser do registro: sua forma e conteúdo. No caso particular aqui examinado, percebe-se que as informações presentes na dramaturgia do espetáculo Quem tem boca, vai a Roma, quem tem sorte, ao Polo Norte, a maneira como essas são dispostas no papel, e os recursos gráficos utilizados (como setas e cores) substituem elementos antes essenciais quando se tratava do texto dramático e do seu epicentro, a fábula: personagem e diálogo (e talvez, por consequência, rubrica). Isto porque nenhum desses dois elementos estiveram presentes no processo de criação, conforme foi anteriormente exposto.

Sendo assim, a prática do palhaço, que se estrutura em torno de outros fundamentos, acabou 
exigindo alternativas de escrita que pudessem servir de anotação de um fazer centrado no corpo e na interação dos corpos. Essas explicitam a busca de outras formas de assentar em um suporte (no caso, aqui, o papel) uma composição que revela táticas diversas de escrita dramatúrgica, as quais fazem da palavra apenas mais um dos recursos encontrados na organização da ação cênica.

Porém, investigar a dramaturgia na sua expansão como conceito no âmbito da cena contemporânea nos faz lembrar, frequentemente, de outros fenômenos teatrais que não gravitam em torno do texto dramático, como a commedia dell'arte. Não sendo o único, o exemplo é bastante oportuno dado algumas similaridades possíveis de serem reconhecidas com o objeto deste estudo. Porque uma das características desse fenômeno é a presença da dramaturgia como uma ferramenta necessária a um trabalho atorial baseado no improviso: o canovaccio. Sua forma e conteúdo - resumidamente, um roteiro onde as ações e falas são narradas - estão vinculados ao fato dele ser um "mecanismo altamente adequado à produção de espetáculos em série e não à busca da montagem de um acervo de obras completas, sempre originais." (RABETTI, 2014, p. 15).

Recuperar, aqui, um fenômeno teatral da era moderna, e colocá-lo ao lado da análise da criação de um espetáculo de palhaço, realizado no tempo de agora, é uma estratégia para evidenciar que a discussão da dramaturgia na cena contemporânea apenas assevera uma realidade que não é nova; trata-se da "pluralidade da arte teatral", "um fenômeno permanente e importante" (GRÉSILLON; MERVANT-ROUX; BUDOR, 2013, p. 388) de ser observado como pressuposto decisivo quando se trata da análise dos vestígios do fazer artístico. Isto obriga, consequentemente, a pensar um documento de teatro - como a dramaturgia, por exemplo - enquanto representação da atividade da qual ele é expressão, ação realizada como ato de criação da cena, sempre legitimado pelo contexto histórico-cultural na qual está inserido.
Esta consciência assevera uma leitura do vestígio do fazer teatral em virtude "de sua natureza, de sua concepção, de seu uso e de sua finalidade" (PROUST, 2010, p. 73, tradução nossa). Desse modo, o estudo do registro deve "revelar sua necessidade no desenvolvimento de sua criação" (PROUST, 2010, p. 86, tradução nossa). Sua potencialidade, em termos informacionais, implica, na verdade, o desvendamento da conjuntura que cerca seu surgimento, pois é aí que está o motivo da imprescindibilidade e do pragmatismo que caracteriza qualquer produção documental, inclusive a da dramaturgia - quando essa sobra como vestígio.

Essa indissociabilidade do vestígio do fazer teatral com a cena, aqui explorada através da discussão da dramaturgia, reforça que a criação e a organização da ação é o que fundamenta o acontecimento cênico, em vista da diversidade do fazer que caracteriza a própria construção da linguagem teatral, em diálogo permanente com tradições e desvios que cercam o desenvolvimento do campo onde a experiência estética se faz presente.

\section{Referências}

BESSON, Jean-Louis. Pós-dramático. In: SARRAZAC, Jean-Pierre (Org.). Léxico do drama moderno e contemporâneo. São Paulo: Cosac Naify. p. 146147, 2012.

CHACOVACHI, Payaso (Fernando Chacovachi Cavarozzi). Manual e Guia do Palhaço de Rua. Buenos Aires: Editora Coletivo Contramar. Trad. Jeff Vasques. 2016.

DANAN, Joseph. Mutações da dramaturgia: tentativa de enquadramento (ou de desquadramento). Moringa - Artes do Espetáculo, João Pessoa, v.1, n.1, p. 117-123, jan. 2010.

DANAN, Joseph. Qu'est-ce que la dramaturgie?. 2 ed. Actes Sud: Paris, 2017. 
DANAN, Joseph. A Dramaturgia no Tempo do "Pós-Dramático". Revista Cena, Porto Alegre, n. 29, p. 14-23, 2019.

FÈRAL, Josette. A Fabricação do Teatro: questões e paradoxos. Revista brasileira de estudos da presença, Porto Alegre, v. 3, n. 2, p. 566-581, 2013.

FONTANA, Fabiana. O que existe de permanente no reino do efêmero - os arquivos pessoais e o patrimônio documental do teatro. Revista Sala Preta, São Paulo, v. 17, n. 2, p. 11-25, 2017.

GRÉSILLON, Almuth; MERVANT-ROUX, MarieMadeleine; BUDOR, Dominique. Por uma Genética Teatral: premissas e desafios. Revista brasileira de estudos da presença, Porto Alegre, v. 3, n. 2, p. 379403, 2013.

KIEVE, Paul. Hocus Pocus: uma história de mágicos magníficos e suas incríveis façanhas. São Paulo: Editora DCL, 2008.

LA VEILLÉE DES ABYSSES. Direção: James Thiérrée. Produção: Agat Films \& La Compagnie du Hanneton. [s.l.]. 2016. (80m16s). Disponível em: https:// www. youtube.com/watch?v=IDETIx7w7N8\&t=33s. Acesso em: 15 jun. 2020.

NETO, Walter Lima Torres. Ensaios de Cultura Teatral. Jundiaí (SP): Paco Editorial, 2016.

OLIVEIRA, Denivaldo Camargo de. Formação em Palhaço: Reflexões sobre metodologias de formação de novos palhaços. 2012. 169 f. Dissertação (Mestre em Artes) - Instituto de Artes, Universidade de Brasília, Brasília, 2012.

POMMERAT, Joël. Théâtre en Présence. 2 ed. Paris: Actes Sud, 2016.
PROUST, Sophie. Les écrits de l'assistant à la mise en scène. In: GRÉSILLON, Almuth; MERVANTROUX, Marie-Madeleine; BUDOR, Dominique. (Eds.). Genèse théâtrales. Paris: CNRS ÉDITIONS, p. 71-86, 2010.

RABETTI (Beti Rabetti), M. de L. A commedia dell'arte: mito, profissão e arte. Artcultura, Uberlândia, v. 16, n. 29, p. 7-17, 2014.

REIS, Demian Moreira. Caçadores de risos: o maravilhoso mundo da palhaçaria. Salvador: EDUFBA, 2013.

SLAVA'S SNOWSHOW. Direção: Slava Polunin. Produção: La Compagnie des Indes. [s.I.]. 2016. (59m57s) Disponível em: https://ok.ru/video/85491845864. Acesso em: 20 ago. 2018.

Recebido: 13/08/2020

Aceito: 06/04/2021 Aprovado para publicação: 27/05/2021

Este é um artigo de acesso aberto distribuído sob os termos de uma Licença Crea- tive Commons Atribuição 4.0 Internacional. Disponível em: http://creativecommons.org/licenses/by/4.0.

This is an open-access article distributed under the terms of the Creative Commons Attribution License 4.0 International. Available at: http://creativecommons.org/licenses/by/4.0.

Ce texte en libre accès est placé sous licence Creative Commons Attribution 4.0 International. Disponible sur: http://creativecommons.org/licenses/by/4.0. 